Universidade de São Paulo

Instituto de Física

\title{
Viabilidade da medida de elementos-traço em soro sanguíneo para diagnóstico de melanoma
}

\author{
Suene Bernardes dos Santos
}

Orientador: Prof. Dr. Manfredo Harri Tabacniks

Tese de doutorado apresentada ao Instituto de Física para a obtenção do título de Doutor em Ciências

\section{Comissão examinadora:}

Prof. Dr. José Fernando D. Chubaci - (IFUSP)

Prof. Dr. Alvaro Vannucci (IFUSP)

Prof. Dr. Carlos R. Appoloni (UEL)

Prof $^{\mathrm{a}}$. Dr ${ }^{\mathrm{a}}$. Ivone Mulako Sato (IPEN) 


\section{FICHA CATALOGRÁFICA}

\section{Preparada pelo Serviço de Biblioteca e Informação}

do Instituto de Física da Universidade de São Paulo

Santos, Suene Bernardes dos

Viabilidade da medida de elementos-traço em soro sanguíneo para diagnóstico de melanoma.

São Paulo, 2012.

Tese (Doutorado) - Universidade de São Paulo. Instituto de Física, Depto. Física Aplicada.

Orientador: Prof. Dr. Manfredo Harri Tabacniks

Área de Concentração: Física

Unitermos: 1. Ciências Exatas; 2. Física; 3. Física Experimental.

USP/IF/SBI-080/2012 
Dedico este trabalho à minha família. 


\section{Agradecimentos}

Ao meu orientador Dr. Manfredo Harri Tabacniks pela dedicação, paciência e apoio durante a realização deste trabalho. Muito obrigada pelo incentivo, pela colaboração intelectual e, principalmente, por ter acreditado neste trabalho.

Ao professor Dr. Jorge Eduardo de Souza Sarkis que disponibilizou o laboratório para a realização das medidas com ICP-MS, orientou as medidas, tirou dúvidas sobre o equipamento e sobre a metodologia adotada.

Aos colaboradores do Hospital São Paulo: Dr. Ivan Abranches Oliveira Santos, Dr. Andrea Fernandes de Oliveira e Janaína Namba Shie. Eles foram de suma importância na obtenção do Comitê de ética do Hospital São Paulo e responsáveis pela coleta das amostras.

Ao colaborador Francisco de Assis Ribas Bosco pelas importantes discussões sobre o trabalho.

À Fundação de Amparo à Pesquisa do Estado de São Paulo, FAPESP, pelo apoio financeiro, possibilitando a conclusão deste trabalho.

À pesquisadora Dr. Teresa Pinheiro que me orientou durante o estágio realizado no ITN (Instituto Tecnológico e Nuclear) em 2009.

À Dra. Maria Julia Manso Alves que disponibilizou o Laboratório de Bioquímica de Parasitas para a liofilização das amostras.

Ao meu namorado e companheiro de todas as horas Antonio Carlos da Silva. Muito obrigada pelo apoio, carinho e dedicação durante os últimos anos. 
Aos técnicos do laboratório LAMFI, Dr. Tiago Fiorini, Dr. Marcel (técnico no início do trabalho), Marquinhos, Renan e Alisson pelo auxilio no laboratório, pela ajuda no processamento das amostras, dúvidas sanadas, manutenção dos equipamentos e organização geral do laboratório.

Ao Tiago Fiorini pelas discussões e ajuda com a análise dos dados, ao Marcos Moro pela ajuda com a impressão da tese e discussões e ao Vinícius Zagatto pela ajuda com o abstract.

Aos professores do grupo de Física Nuclear Aplicada, Márcia de Almeida Rizzutto e Nemitala Added, pelo apoio e colaboração no andamento do trabalho.

A toda minha família que tanto amo, em especial à minha mãe Vaina Bernardes, ao padrasto Valmir, à tia Aparecida (tia Pepê), à minha avó Maria (dona Cóta) e ao meu avô Sebastião (em memória), ao tio José Francisco, às minhas irmãs Niele e Andreza e aos meus sobrinhos Arthur Henrique e Luiz Hermano, que são a maior alegria da família. Agradeço também ao meu pai Wilson, madrasta Vilma e irmãos Júnior, Leonardo e Laura pelo apoio e carinho.

À minha segunda família: Júbio, Rosinha e Mimi pelo carinho.

Aos 146 doadores que LITERALMENTE deram o sangue pelo meu trabalho.

Aos amigos que muito ajudaram e apoiaram em todos os momentos: Márcia, Bebeto, Paty, Elis, Julian (Bá), Adriana Barioni, Adriana Delgado, Viviane, Anne, Maria, Marcelos, Djalma, Brenda, Gabi, Vini, Hellen, Roberto, Jéssica, Pedro, Marcos, Valdir, Chris, Pietro entre outros.

Aos amigos do grupo de Física Nuclear Aplicada e do Crusp.

Aos amigos de Londrina e Frutal, que mesmo de longe colaboraram com este trabalho, dando apoio nas horas difíceis e dividindo os bons momentos também. 


\section{Resumo}

A medida e o controle de elementos químicos, majoritários ou traço, em tecidos e fluídos biológicos, vem sendo utilizada há muito tempo para diagnósticos médicos, em avaliações de saúde, estado nutricional e para prevenção e acompanhamento de doenças. Em muitos casos tal relação já foi solidamente estabelecida, mas no estudo de neoplasias, ainda se busca relação entre teores químicos elementares e vários tipos (ou estágios) de câncer. Nesse tipo de estudo utilizam-se métodos espectroscópicos multi-elementares de altíssima sensibilidade ainda não disponíveis rotineiramente em laboratórios clínicos.

Neste trabalho, buscaram-se alterações na concentração de elementos químicos majoritários e traço em soro sanguíneo de pacientes com melanoma, por meio de análises pelos métodos PIXE e HR-ICPMS como auxiliar de diagnóstico desta neoplasia, uma vez que sua detecção em estágios iniciais aumenta a probabilidade de recuperação. A técnica PIXE (Proton Induced X-ray Emission) de análise multi-elementar baseia-se na detecção de raios X característicos, enquanto o HR-ICPMS (High Resolution Inductively Coupled Plasma Mass Spectrometry) é um espectrômetro de massa de alta resolução. As amostras de sangue de 30 pacientes e 116 doadores sadios foram coletadas no Hospital São Paulo (protocolos CEP 1036/08 UNIFESP) em tubos de vidro sem aditivos, sendo o soro separado por meio de centrifugação a 4500 rpm durante 15 minutos.

Foram identificados e quantificados um total de 10 elementos: 4 por HR-ICPMS (Mg, $\mathrm{Se}, \mathrm{Cu}$ e $\mathrm{Zn})$ e 8 por PIXE (P, S, Cl, K, Ca, Br, $\mathrm{Cu}$ e $\mathrm{Zn}$ ). Os métodos analíticos foram aferidos com os materiais de referência QMEQAS06S-06, QMEQAS08S-06 e NIST 1577b. A precisão analítica variou de $3 \%$ a $9 \%$ para ambas as técnicas. As informações clínicas relevantes dos pacientes foram incluídas na análise (tipo histológico do tumor; nível de melanoma; escala de Breslow em profundidade; número de linfonodos; presença ou ausência de mitose e/ou ulceração). A avaliação do grupo controle mostrou diferentes concentrações de $\mathrm{P}$ e $\mathrm{Mg}$ para indivíduos com idade acima ou abaixo de 40 anos. Os teores de $\mathrm{P}, \mathrm{S}, \mathrm{Ca}, \mathrm{Cu}$ e $\mathrm{Zn}$ 
em indivíduos saudáveis apresentaram diferenças com o gênero, evidenciando a necessidade de inserir estas variáveis na análise caso-controle. As concentrações de $\mathrm{K}, \mathrm{S}, \mathrm{Ca}$ e $\mathrm{Se}$ apresentaram diferença entre os grupos controle e melanoma, quando consideradas as variáveis clínicas dos pacientes $(\mathrm{p}<0,05)$. A necessidade de estratificação por idade, gênero e estágio da neoplasia, reduziu criticamente o já limitado espaço amostral, comprometendo a interpretação das pequenas diferenças nas concentrações elementares encontradas. Os resultados encontrados para a população sadia concordaram com os valores publicados na literatura e colaboraram para o fortalecimento do banco de dados de concentrações elementares em soro da população brasileira.

Palavras-chave: Soro, Melanoma, Elementos-traço, PIXE, HR-ICPMS 


\section{Abstract}

Recording chemical elements, either as major or trace quantities, in tissues and biological fluids is regularly being used for medical diagnosis, health assessments, nutritional status, and for the monitoring and prevention of diseases. In many cases, such relationship is firmly established, but for cancer, there is still a search for a relationship between chemical elements and various types (or stages) of cancer. In this kind of study, highly sensitive multielemental spectroscopic methods are used which are not yet routinely available in clinical laboratories.

In this study, changes in the concentration of chemical elements in serum of melanoma patients were sought by means of PIXE and HR-ICPMS analysis as an aid to early diagnosis, and to help increasing the likelihood of pacient's recovery. The multi-elemental PIXE method (Proton Induced X-ray Emission) relies on the detection of characteristic X-rays of the sample, while the HR-ICPMS (High Resolution Inductively Coupled Plasma Mass Spectrometry) is a high resolution mass spectrometer. Blood samples from 30 patients and 116 healthy donors were collected at the Hospital (protocols CEP 1036/08 UNIFESP) in glass tubes without additives, and the serum separated after centrifugation for 15 minutes at $4500 \mathrm{rpm}$.

A total of 10 elements were measured: 4 by HR-ICPMS (Mg, Se, $\mathrm{Cu}$ and $\mathrm{Zn}$ ), 8 by PIXE (P, S, Cl, K, Ca, Br, $\mathrm{Cu}$ and $\mathrm{Zn}$ ). The analytical methods were assessed analyzing reference materials QMEQAS06S-06, QMEQAS08S-06 and NIST 1577b. The analytical precision ranged from $3 \%$ to $9 \%$. Relevant clinical information of patients has also been included in the statistical analysis (histological type of tumor, level of melanoma, Breslow depth scale, number of lymph nodes, presence or absence of mitosis and/or ulceration). The evaluation of the control group showed different concentrations of $\mathrm{P}$ and $\mathrm{Mg}$ for individuals aged above and below 40 years. The $\mathrm{P}, \mathrm{S}, \mathrm{Ca}, \mathrm{Cu}$ and $\mathrm{Zn}$ in healthy individuals differed according to the gender, highlighting the need of inserting the variables age and gender in the case-control analysis. The concentrations of $\mathrm{K}, \mathrm{S}, \mathrm{Ca}$ and $\mathrm{Se}$ showed differences between the 
control group and the melanoma, when considering the clinical variables of the patients ( $p$ $<0.05)$. The need for stratification by age, gender and stage of cancer, critically reduced the already limited number of samples, compromising the interpretation of the small differences in elemental concentrations found. The results for the healthy population agreed with the values reported in the literature and contributed to strengthen the database of elemental concentrations in serum of the Brazilian population.

Key words: Serum, Melanoma, Trace Elements, PIXE, HR-ICPMS 


\section{Lista de Abreviações}

AAS: Atomic Absorption Spectrometry.

ABCD: assimetria, borda, cor, diâmetro.

AP: Adição de padrão.

B: espessura de Breslow.

C: grupo controle.

$\mathrm{CO}_{2}$ : gás carbônico

DA: digestão ácida.

DRC: célula de reação dinâmica.

HR-ICPMS: High Resolution Inductively Coupled Plasma Mass Spectrometry.

ICP-AES: Inductively Coupled Plasma Atomic Emission Spectroscopy.

ICP-OES: Inductively Plasma Optical Emission Spectrometry.

ICP-MS: Inductively Coupled Plasma Mass Spectrometry.

IFUSP: Instituto de Física da USP.

IPEN: Instituto de Pesquisas Energéticas e Nucleares.

L: linfonodos.

LAMFI: Laboratório de Análise de Materiais por Feixes Iônicos.

LD: limite de detecção.

LQ: limite de quantificação.

LTA: Low Temperature Ashing.

M: grupo melanoma.

MCN: nebulizador microconcêntrico.

$\mathrm{m} / \mathrm{z}$ : razão massa/carga.

NAA: Neutron Activation Analysis.

NEC: National Electrostatic Corporation.

PIXE: Particle Induced X-ray Emission. 
PN: nebulizador pneumático.

ppb: parte por bilhão ou $\mu \mathrm{g} \mathrm{kg}^{-1}$.

ppm: parte por milhão ou $\mathrm{mg} \mathrm{kg}^{-1}$.

ppt: parte por trilhão ou ng $\mathrm{kg}^{-1}$.

$\mathrm{RF}$ : radiofrequência.

SNICS: Source of Negative Ions by Cesium Sputtering.

TH: tipo histológico.

TXRF: Total Reflection X-ray Fluorescence

uma: unidades de massa.

USN: nebulizador ultra-sônico. 


\section{Índice}

1 Introdução 1

1.1 Função biológica de alguns elementos 3

1.2 Sangue 4

1.3 Melanoma

1.3.1 Tipos de melanoma 5

1.4 Diagnóstico 7

1.5 Objetivos 8

2 Revisão Bibliográfica 99

2.1 Elementos traço e o câncer 13

3 A Técnica PIXE 17

3.1 Introdução 17

3.2 Fundamentos Físicos 17

3.3 Arranjo Experimental 19

3.4 Formulação PIXE 20

3.5 Limite de Alvos Finos 23

3.6 Medidas Relativas por Dopagem 24

3.7 Detectores Semicondutores 25

4 A Técnica HR-ICPMS 27

$\begin{array}{ll}4.1 \text { Introdução } & 27\end{array}$

4.2 Introdução de Amostras 28

4.3 Fonte de Íons - Tocha e Plasma 29

4.4 Interface 31

4.5 Analisadores 32

4.5.1 Analisadores de Massa Quadrupolares 32

4.5.2 Analisadores de Dupla focalização 33 
4.6 Sistemas de Detecção 34

4.6.1 Multiplicador de Elétrons 35

4.7 Interferências Espectroscópicas 35

4.7.1 Interferências Isobáricas 35

4.7.2 Interferências por Íons Poliatômicos 36

4.7.3 Íons de Dupla Carga 36

4.7.4 Interferências por Espécies Óxido e Hidróxido 37

$\begin{array}{lll}4.8 \text { Resolução } & 37\end{array}$

5 Materiais e métodos 40

$\begin{array}{ll}\text { 5.1 Pesquisadores envolvidos } & 40\end{array}$

5.2 Comitê de Ética em Pesquisa 41

5.3 Cuidados laboratoriais 41

5.3.1 Materiais descartáveis 41

5.3.2 Materiais reutilizáveis 41

5.3.3 Padrões e reagente 42

$\begin{array}{ll}\text { 5.3.4 Laboratórios } & 42\end{array}$

5.4 Coleta das amostras $\quad 43$

5.5 Preparação de amostras 44

$\begin{array}{ll}\text { 5.5.1 PIXE } & 44\end{array}$

5.5.1.1 Adição de Padrão (AP) 46

5.5.1.2 Digestão Ácida (DA) 47

$\begin{array}{ll}\text { 5.5.2 HR-ICPMS } & 48\end{array}$

$\begin{array}{ll}5.6 & \text { Equipamentos utilizados }\end{array}$

5.6.1 O Sistema PIXE do LAMFI - IFUSP 49

5.6.2 O Sistema HR-ICPMS do LCQI- IPEN 50

5.7 Observações $\quad 52$

6 Avaliação de Método

6.1 Curvas de calibração 53

6.1.1 PIXE 54

6.1.2 HR-ICPMS 55

6.2 Precisão 59 
6.3 Exatidão 60

6.4 Limites de detecção e quantificação 63

$\begin{array}{lll}\text { 6.4.1 PIXE } & 64\end{array}$

6.4.2 HR-ICPMS $\quad 65$

7 Resultados e Discussões 66

$\begin{array}{lll}7.1 & \text { Análise de agrupamento } & 70\end{array}$

7.2 Análise fatorial 73

7.3 Análise do grupo controle 75

7.4 Análise do grupo melanoma 80

7.5 Análises MANOVA e Kruskal-Wallis $\quad 81$

8 Conclusões 86

Referências $\quad 89$

ANEXO A: Classificação do melanoma

ANEXO B: Célula de reação dinâmica $\quad 98$

ANEXO C: Carta de consentimento e do histórico de saúde 100

ANEXO D: Protocolo de descontaminação de matérias 103

$\begin{array}{ll}\text { ANEXO E: Liofilização } & 104\end{array}$

ANEXO F: Testes estatísticos 106 


\section{Introdução}

A identificação e a quantificação de elementos químicos em materiais biológicos têm crescido muito nos últimos anos. Eles estão presentes nos sistemas biológicos em geral e muitos são essenciais para a vida porque desempenham importantes funções nos processos bioquímicos dos seres vivos, ou seja, são relevantes para o bom funcionamento dos organismos. O monitoramento contínuo desses elementos atrai grande interesse clínico porque permite avaliar a condição de saúde da população em relação à contaminação ou insuficiência nutricional e aos riscos de exposição excessiva por metais tóxicos. Este tipo de pesquisa também vem sendo aplicada em estudos médicos e muitos mostraram relação entre a alteração dos níveis elementares e a eclosão de diversas doenças, incluindo vários tipos de câncer [Hasegawa, 2001; Hernández-Caraballo, 2003; Pinheiro, 1994 e Sisti, 2001].

Os elementos químicos encontrados nos organismos vivos podem ser divididos em três grupos de acordo com os seus teores esperados: os majoritários são os que constituem a matriz $(\mathrm{H}, \mathrm{C}, \mathrm{N}$ e O $)$ e alguns elementos presentes numa concentração da ordem de $\mathrm{mg} \mathrm{g}^{-1}(\mathrm{Mg}, \mathrm{P}, \mathrm{S}$, $\mathrm{Cl}, \mathrm{K}$ e $\mathrm{Ca}$ ); os traço são aqueles presentes num intervalo de concentração entre $100 \mu \mathrm{g} \mathrm{g}^{-1} \mathrm{e}$ $0,01 \mu \mathrm{g} \mathrm{g}^{-1}$; enquanto o termo ultra-traço é aplicado aos elementos com concentrações inferiores a $0,01 \mu \mathrm{g} \mathrm{g}^{-1}$ na amostra. Entre os elementos-traço e ultra-traço estão $\mathrm{Co}, \mathrm{Cu}, \mathrm{Cr}, \mathrm{I}$, Mn, Mo, Ni, Se, V, Fe, Zn, As, Pb, Hg e Cd. Alguns destes elementos, como o Pb, Hg e Cd, são potencialmente tóxicos e muitos são considerados essenciais $(\mathrm{Co}, \mathrm{Cu}, \mathrm{Cr}, \mathrm{I}, \mathrm{Mn}, \mathrm{Mo}, \mathrm{Ni}$, $\mathrm{Se}, \mathrm{Fe}$ e $\mathrm{Zn}$ ); mas mesmo os essenciais podem se tornar tóxicos se suas concentrações excederem os valores máximos de segurança [Pinheiro, 1994; Santos, 2007 e Sisti, 2001].

O foco deste trabalho é estudar o teor de elementos majoritários e traço em pacientes com melanoma e verificar se existem alterações que possam ser correlacionadas com a doença. Recentemente, alguns pesquisadores têm considerado possíveis relações entre a concentração dos elementos e a ocorrência da doença [Fisher,1981; Gorodetsky, 1986; RosBullon, 1998 e Bergomi, 2005]. Entretanto, estudos mais detalhados são necessários para 


\section{Referências}

Aburaya, J.H., Padronização de amostras espessas para análise PIXE, Dissertação de Mestrado, Instituto de Física, USP, São Paulo, (2005).

Azevedo, G. e Mendonça, S., Risco crescente de melanoma de pele no Brasil, Rev. Saúde Pública, São Paulo, 26(4): 290-294 (1992).

Azin, F., Raie, R.M. e Mahmoudi, M.M., Correlation between the levels of certain carcinogenic and anticarcinogenic trace elements and esophageal cancer in Northern Iran, Ecotoxicology and Enviromental Safety, 39: 179-184 (1998).

Bakos, L., Melanoma cutâneo: estudos de base populacional no Brasil, An. Bras.Dermatol., 81(5): 402 (2006).

Bergomi, M., Pellacani, G., Vinceti, M., Bassissi, C.M., Alber, D., Sieri, S., Vescovi, L., Seidenari, S. e Vivoli, R., Environmental exposure to trace elements and risk of cutaneous melanoma, Journal of Trace Elements in Medicine and Biology, 19: 69-73 (2005).

Bernardes, S., Tabacniks, M. H., Added, N., Rizzutto, M. A., Barbosa, M. D. L., Martinez, M. e Machado, J., Trace elements in blood serum of São Paulo youths measured by PIXE, International Journal of PIXE (IJPIXE) 18: 139-145 (2008).

Besteman, A.D., Bryan, G.K., Lau, N. e Winefordner, J.D., Multielement Analysis of Whole Blood Using a Capacitively Coupled Microwave Plasma Atomic Emission Spectrometer, Microchemical Journal, 61: 240-246 (1999).

Bevington, P.R., Data Reduction And Error Analysis For The Physical Sciences, New York (1969).

Bianchi, F., Maffini, M., Mangia, A., Marengo, E. e Mucchino, C., Experimental design optimization for the ICP-AES determination of $\mathrm{Li}, \mathrm{Na}, \mathrm{K}, \mathrm{Al}, \mathrm{Fe}, \mathrm{Mn}$ and $\mathrm{Zn}$ in human serum, Journal of Pharmaceutical and Biomedical Analysis, 43: 659-665 (2007).

Conover, W.J. Practical Nonparametric Statistics. Wiley series in probability and mathematical statistics 2nd, 493 (1980).

Currie, L.A., Limits for Qualitative Detection and Quantitative Determination Analytical Chemistry, 40 (3): 586-593, (1968).

Dean, J.R., Practical Inductively Coupled Plasma Spectroscopy, Northumbria University, Newcastle, UK (2005). 
Dimatos, D.C., Duarte, F.O., Machado, R.S., Vieira, V.J., Vasconcellos, Z.A.A, Bins-Ely, J. e Neves, R.D., Melanoma cutâneo no Brasil, Arquivos Catarinenses de Medicina, 38: 14-19 (2009).

Dobrowolski, Z., Drewniak, T., Kwiatek, W. e Jakubik, P., Trace elements distribution in renal cell carcinoma depending on stage of disease, European Urology, 42: 475-480 (2002).

Domnanich, P., Sauer, U., Pultar, J. e Preininger, C., Protein microarray for the analysis of human melanoma biomarkers, Sensors and Actuators B: Chemical, 1-7 (2008).

Ebrahim, A.M., Eltayeb, M.A.H., Shaat, M.K., Mohmed, N.M.A., Eltayeb, E.A. e Ahmed, A.Y., Study of selected trace elements in cancerous and non-cancerous human breast tissues from Sudanese subjects using instrumental neutron activation analysis, Science of the Total Environment, 383: 52-58 (2007).

Fauri, J.A.C., Diehl, E.S., Cartell, A. e Edelweiss, M.I.A., A proteína p16 e o melanoma cutâneo, Revista da AMRIGS, Porto Alegre, 54(1): 81-91 (2010).

Ferreira, L.M., Guia de cirurgia plástica, 1ª . ed., Manole, São Paulo, 269-283 (2007).

Fisher, G.L., Spitler, L.E., McNeill, K.L. e Rosenblatt, L.S., Serum Copper and Zinc in Melanoma Patients, Cancer, 47: 1838-1844 (1981).

Furusawa, H.A., Razão Isotópica de Enxofre em Material Atmosférico por ICP-MS de Alta Resolução, Tese de Doutorado, Instituto de Química, USP, São Paulo (1999).

Giné-Rosias, M.F., Espectrometria de Massas com Fonte de Plasma (ICP-MS), CGP/CENA. Piracicaba, Brasil. (1999).

Gorodetsky, R., Sheskin, J. e Weinred, A., Iron, copper, and zinc concentrations in normal skin and in various nonmalignant and malignant lesions, Int. J. Dermatol, 25: 440-450 (1986).

Hair Jr., J.F., Black, W.C., Babin, B.J., Anderson, R.E. e Tatham, R.L., Análise multivariada de dados, editor Bookman, 6 a ed., Porto Alegre (2009).

Hampe, S.V., Estudo da precocidade diagnóstica dos melanomas cutâneos primários em Porto Alegre, por análise de imagem computadorizada, Dissertação de mestrado, Universidade Federal do Rio Grande do Sul, Porto Alegre (1997).

Hasegawa, T., Inagaki, K. e Haraguchi, H., Multielement correlation analysis of major-totrace elements in human blood serum for medical diagnosis as studied by ICP-AES and ICP-MS, Analytical Sciences, 17: 979-982 (2001).

Hattendorf, B. e Günther, D., J. Anal. At. Spectrom., 15: 1125-1131 (2000).

Hernández-Caraballo, E.A. e Marcó-Parra, L.M., Direct analysis of blood serum by total reflection X-ray fluorescence spectrometry and application of an artificial neural network approach for cancer diagnosis, Spectrochimica Acta Part B, 58: 2205-2213 (2003). 
Huang, Y.L., Sheu, J.Y. e Lin, T.H., Association between oxidative stress and changes of trace elements in patients with breast cancer, Clinical Biochemistry, 32 (2): 131-136 (1999).

INMETRO DOQ-CGRE-008, Orientação sobre validação de métodos analíticos, Revisão Julho (2011).

Jenkins, R., Gould R.W. e Gedke, D., Quantitative X-ray Spectrometry, Marcel Dekker, New York, USA (1981).

Johansson, T.B., Akselsson, K.R. e Johansson, S.A.E., X-Ray Analysis: elementaltrace analysis at 10-12 $\mathrm{g}$ level, Nucl. Instr. Meth., 84: 141-143 (1970).

Johansson S.A.E. e Campbell, J.L., PIXE: A Novel Technique for Elemental Analysis, Wiley, New York (1988).

Jung, J.E., Expressão dos genes Braf e C-kit e sua correlação com fatores prognósticos em melanomas cutâneos, Tese de Doutorado, Universidade Federal do Paraná, Curitiba (2010).

Kolaric, K., Roguljic, A. e Fuss, V., Serum copper levels in patients with solid tumors, Tumori, 61(2): 173-177 (1975).

Kubala-Kukus, A., Braziewcz, J., Banas, D., Majewska, U., Gozdz, S. e Urbaniak, A., Trace element load in cancer and normal lung tissue, Nuclear Instruments and Methods in Physics Research B, 150: 193-199 (1999).

Labconco, A guide to freeze drying for the laboratory, by labconco corporation (1998).

Lecomte, R., Landsberger, S. e Monaro, S. Evaluation of trace-element sensitivities in PIXE analysis of low-temperature-ashed serum samples. The International journal of applied radiation and isotopes, 33: 121-125 (1982).

Leighton, R.B. Principles of Modern Physics. McGraw-Hill (1959).

Lima, G.A.M.R., Relações entre migração e redistribuição de umidade sobre a qualidade e estabilidade do peixe pintado liofilizado, tese de doutorado, USP, São Paulo (2004).

Marcó P.L.M., Jiménez, E., Hernández, C.E.A., Rojas, A. e Greaves, E.D., Determination of $\mathrm{Zn} / \mathrm{Cu}$ ratio and oligoelements in serum samples by total reflection $\mathrm{X}$-ray fluorescence spectrometry for cancer diagnosis, Spectrochimica Acta B, 56: 2195-2201 (2001).

Margulis, W., Implantação do Método de Análise por PIXE e Aplicação na Análise de Aerossóis, Dissertação de mestrado, Departamento de Física, PUC. Rio de Janeiro (1977).

Martínez-Espinosa, M., Calil Jr, C., e Lahr, F.A.R. Métodos paramétricos e nãoparamétricos para determinar o valor característico em resultados de ensaio de madeira. Scientia Forestalis, 66:76-83 (2004).

Massey, F.J., Jr. The Kolmogorov-Smirnov Test for Goodness of Fit. Journal of the American Statistical Association, 46, 68-78 (1951).

Maxwell, J.A., Campbell, J.L. e Teesdale, W.J., The Guelph PIXE software package, Nucl. Instr. Meth. Phys. Res., B 43: 218-30 (1989). 
Mc Leon, J.A., Minnich, M.G., Iacom, L.A., LuiI, H. e Montaser, A., Journal of Analytical Atomic Spectrometry, 13: 829-842, (1998).

Mellor, J.D., Fundamentals of Freeze-Druing, academic press (1987).

Mingoti, S.A., Análise de dados através de métodos de estatística multivariada, editora UFMG, Belo Horizonte (2007).

Montaser, A., Inductively Coupled Plasma Mass Spectrometry, USA, (1998).

Motta, V.T., Bioestatística, $2^{\text {a }}$ ed., cap. 6 e 12, Editora EDUCS, Caxias do Sul, RS, Brasil (1996).

Müller, R.M.L., Podem ser os metais utilizados no diagnóstico do diabetes mellitus tipo 2?, Dissertação de mestrado, IPEN, São Paulo (2008).

National Cancer Institute, disponível em <http://visualsonline.cancer.gov/searchaction.cfm?q=melanoma>, acessado dia 16 de outubro de 2012.

Navarro, M.S., A implantação de rotina, e seu refinamento, para a determinação de elementos terras raras em materiais geológicos por ICP-OES e ICP-MS. Aplicação ao caso dos granitóides de Piedade-Ibiúna (SP) e Cunhaporanga (PR), Tese de Mestrado, IGUSP, (2004).

Navarro-Alarcón, M., López-G de la Serrana, H., Pérez-Valero, V e López-Martínez, C., The Science of the Total Enviroment, 212: 195-202 (1998).

Neubauer, K. e Völlkopf, U., Atomic Spectroscopy, 20(2): 64-68 (1999).

Pedreira Filho, W.R., Determinação de Impurezas Metálicas em Óxidos de Terras Raras de Alta Pureza Pela Espectrometria de Massa (Setor Magnético) com Fonte de Plasma Induzida por Argônio (HR ICP-MS) e Cromatografia Líquida de Alto Desempenho (HPLC), Tese de Doutorado, IPEN, USP, São Paulo (2000).

Pinheiro, M.T.F.M, Biologia dos Elementos Vestigiais na Aterosclerose, Tese de doutorado, Faculdade de Ciências da Universidade de Lisboa, Lisboa, Portugal (1994).

Pinho, A.G., at al, An. Acad. Brasil. Ciên., 51(3): 365-393, (1979).

Portal de Estudos em Química, disponível em <http://www.profpc.com.br/propriedades_coligativas.htm>, acessado dia 16 de outubro de 2012.

Potts, P.J., A Handbook of Silicate Rock Analysis, Blackie Academic \& Professional (1987).

Rodushkin, I., Ödman, F. e Branth, S., Multielement analysis of whole blood by high resolution inductively coupled plasma mass spectrometry, Fresenius J. Anal. Chem., 364: 338-346 (1999).

Rodushkin, I., Ödman, F., Olofsson, R. e Axelsson, M.D., J. Determination of 60 elements in whole blood by sector field inductively coupled plasma mass spectrometry, Anal. At. Spectrom., 15: 937-944 (2000). 
Ros-Bullon, M.R., Sanchez-Pedreno, P. e Martinez-Liarte, J.H., Serum zinc levels are increased in melanoma patients. An ROC curve analysis Melanoma Res, 8: 273-277 (1998).

Santos, A.C. e Ferreira, D.F., Definição do tamanho amostral usando simulação Monte Carlo para o teste de normalidade baseado em assimetria e curtose: I. Abordagem univariada. Cienc. Agrotec. Lavras, 27(2): 432-437 (2003).

Santos, I.D.A.O, Melanoma cutâneo. In: Forones, N.M., Garcia Filho, R.J., Tadoloro, H., Freire, C.A.R., Guias de medicina ambulatorial e hospitalar, UNIFESP/Escola Paulista de Medicina, Manole, São Paulo, p. 191-205 (2005).

Santos, S.B., Elementos traço em soro Sanguíneo medidos pelos métodos PIXE e ICP-MS, Dissertação de mestrado, IFUSP, São Paulo (2007).

Sisti, C., Aplicação de diferentes metodologias na preparação de matrizes orgânicas para a determinação voltamétrica de elementos traço, Dissertação de mestrado, IPEN, São Paulo (2001).

Skoog, D.A., Holler, F.J. e Nieman, T.A., Princípios de Análise Instrumental, Bookman, (2002).

St'astná, M., Nemcová, I. e Zýka, J., ICP-MS for the Determination of Trace Elements in Clinical Samples, Analytical Letters, 32(13): 2531-2543 (1999).

Stosnach, H. and Mages, M., Spectrochimica Acta Part B, 64: 354-356 (2009).

Tabacniks, M.H., Calibração do sistema PIXE-SP de análise elementar, Dissertação de mestrado, Instituto de Física, USP, São Paulo (1983).

Tabacniks, M.H., Desenvolvimento de metodologia para análise de filtros de fibras de vidro pelo método PIXE, Tese de Doutorado, Instituto de Física, USP, São Paulo (1991).

Tabacniks, M.H., et al, PIXE for Thin Film Analysis, Research Report RJ 10000 (89089) IBM-ARC, (1996).

Tabacniks, M.H. Os Elementos na Matéria, Tese de Livre Docência, Instituto de Física, USP, São Paulo, (2005).

Tanaka, K., Fracionamento do Plasma Bovino para Isolamento da Albumina e sua Liofilização, dissertação de mestrado, USP, São Paulo (1987).

Tanaka, V.S.P., Análise Elementar sub-ppb de Amostras Líquidas pelos Métodos PIXE e STXRF, Dissertação de mestrado, Instituto de Física, USP, São Paulo, (2006).

Tanner, S.D. e Baranov, V.I., Atomic Spectroscopy, 20(2): 45-52 (1999).

Tanner, S.D., Baranov, V.I. e Völlkopf, U., J. Anal. At. Spectrom., 15: 1261-1269 (2000).

The Oncology Institute of Hope \& Innovation. Disponível em <www.theoncologyinstitute.com/>, acessado dia 27 de jun. 2012.

Thomas, R., Practical Guide to ICP-MS - A tutorial for Beginners, Taylor \& Francis Group, $2^{\mathrm{a}}$ ed., New York (2008). 
Thompson, A.C. e Vaughan, D., X-Ray Data Booklet, Lawrence Berkeley National Laboratory, Berkeley, CA, USA, $2^{\mathrm{a}}$ ed, (http://xdb.lbl.gov), (2001).

Ulrich, J.C., Determinação de Impurezas em Compostos de Urânio por meio da Técnica de Espectrometria de Massas de Alta Resolução com Fonte de Plasma Indutivo (HR-ICPMS), Dissertação de Mestrado, IPEN, São Paulo (2001).

Van Espen, P., Janssens, K. \& Swenters, I. AXIL X-Ray Analysis software, Canberra Packard, Benelux (1986).

Van Wylen, G.J. e Sonntag, R.E., Fundamentos da Termodinâmica Clássica, capítulo 3, (1970).

Veiga, M.A.M.S., Determinação de Elementos Traço por AAS e ICP-MS Após Extração no Ponto Nuvem, Usando Dietil-Ditiofosfato Como agente Quelante, Tese de Doutorado, Universidade Federal de Santa Catarina, Florianópolis (2000).

Villela, G.G., Bacila, M. e Tastaldi, H., Bioquímica, Ed. Guanabara, Rio de Janeiro, Brasil (1961).

Vuolo, J.H., Fundamentos da Teoria de Erros, São Paulo/SP, Brasil, 2a edição, 152-153 (1996).

Zar, J., Biostatistical Analysis, Volume: 4th, Issue: 4., Publisher: Prentice Hall, Pages: 663 (1999).

Zarkadas, Ch., Karydas, A.G. e Paradellis, T., Applicability of direct total reflection X-ray fluorescence analysis in the casa of human blood serum samples, Spectrochimica Acta Part B, 56: 2219-2228 (2001). 


\section{Anexo A}

\section{Classificações do melanoma}

O melanoma pode ser classificado de acordo com os nívíes de Clark, níveis de Breslow ou de pelo estadiamento TNM.

\section{A.1 Níveis de Clark}

Os níveis de Clark são classificados em: nível I: situados na epiderme (in situ); nível II: atinge a derme papilar sem ultrapassá-la; nível III: cresce na interface, atinge o limite entre a derme papilar e a derme reticular; nível IV: se espalha pela derme reticular e nível V: invade a hipoderme, figura A.1.

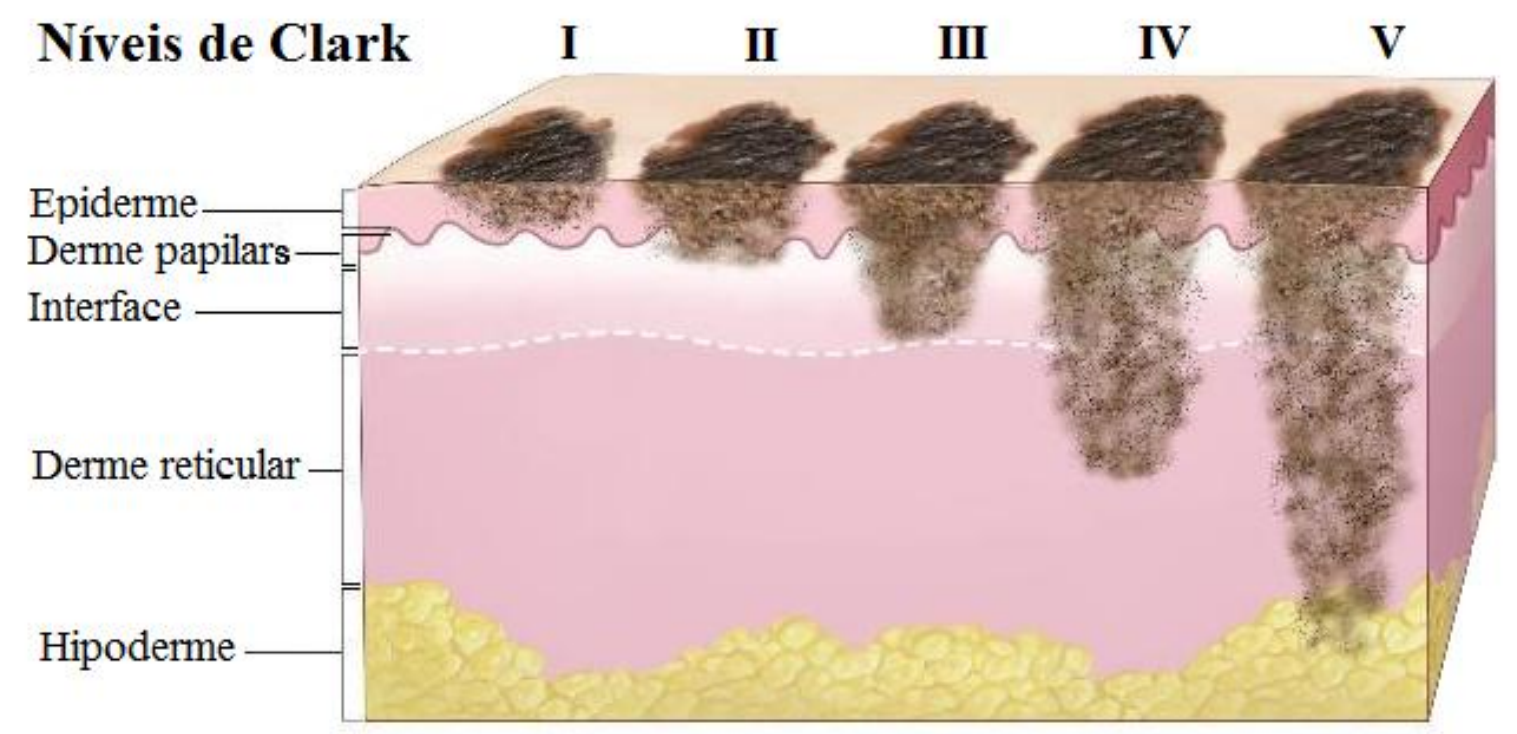

Figura A.1 Níveis de Clark [Adaptado de Melanoma In:The Oncology Institute]. 


\section{A.2 Espessura de Breslow}

A espessura de Breslow classifica o melanoma em relação ao tamanho do tumor em profundidade:

I: espessura <0,75 mm;

II: espessura entre 0,75 e $1,5 \mathrm{~mm}$;

III: espessura entre 1,6 e 3,0 mm;

IV: espessura entre 3,1 e $4 \mathrm{~mm}$;

$\mathrm{V}$ : espessura $>4 \mathrm{~mm}$.

Atualmente este tipo de classificação é mais usado do que os níveis de Clark.

\section{A.3 Estadiamento TNM}

O sistema TNM do American Joint Commitee on Câncer estabelece estágios para o melanoma. Os estádios são classificados de acordo com a extensão anatômica, que por sua vez é baseado em três componentes: a) extensão do tumor (T), b) ausência ou presença de metástase em linfonodos regionais $(\mathrm{N})$ e c) a presença ou ausência de metástase à distância (M). A adição de números às componentes TNM indica a extensão do tumor $\left(\mathrm{T}_{0}, \mathrm{~T}_{1}, \mathrm{~T}_{2}, \mathrm{~T}_{3}\right.$, $\left.\mathrm{T}_{4}, \mathrm{~N}_{0}, \mathrm{~N}_{1}, \mathrm{~N}_{2}, \mathrm{~N}_{3}, \mathrm{M}_{0}, \mathrm{M}_{1}\right)$, tabela A.1. 
Tabela A.1 Classificação TNM do melanoma cutâneo classificado em relação à extensão do tumor (T), presença ou ausência de linfonodos regionais (N) e de metástase (M) [Santos, 2005].

\begin{tabular}{|c|c|c|}
\hline \multicolumn{3}{|c|}{ Tumor Primários (T) } \\
\hline Classificação & Breslow (mm) & Ulceração / Mitoses \\
\hline $\mathrm{T}_{\text {in situ }}$ & Não se aplica & Não se aplica \\
\hline $\mathrm{T} 1$ & $\leq 1,00$ & $\begin{array}{l}\text { a: Sem ulceração e mitose }<1 / \mathrm{mm}^{2} \\
\text { b: Com ulceração ou mitose } \geq 1 / \mathrm{mm}^{2}\end{array}$ \\
\hline $\mathrm{T} 2$ & $1,01-2,00$ & $\begin{array}{l}\text { a: Sem ulceração } \\
\text { b: Com ulceração }\end{array}$ \\
\hline $\mathrm{T} 3$ & $2,01-4,00$ & $\begin{array}{l}\text { a: Sem ulceração } \\
\text { b: Com ulceração }\end{array}$ \\
\hline $\mathrm{T} 4$ & $>4,00$ & $\begin{array}{l}\text { a: Sem ulceração } \\
\text { b: Com ulceração }\end{array}$ \\
\hline \multicolumn{3}{|c|}{ Metástases locorregionais } \\
\hline $\mathbf{N}$ & Número de linfonodos metastáticos & Massa linfonodal metastática \\
\hline No & 0 & NA \\
\hline N1 & 1 & $\begin{array}{l}\text { a: Micrometástases* } \\
\text { b: Macrometástases } \dagger\end{array}$ \\
\hline $\mathrm{N} 2$ & 2 a 3 & $\begin{array}{c}\text { a: Micrometástases* } \\
\text { b: Macrometástases } \dagger \\
\text { c: Metástase em trânsito/ satelitoses, sem } \\
\text { linfonodo metastático }\end{array}$ \\
\hline N3 & $\begin{array}{l}\geq 4 \text { linfonodos metastáticos, linfonodos } \\
\text { confluentes ou metástase em trânsito/ } \\
\text { satelitoses com linfonodos metastáticos }\end{array}$ & \\
\hline \multicolumn{3}{|c|}{ Metástases à distância } \\
\hline $\mathbf{M}$ & \multicolumn{2}{|c|}{ Local } \\
\hline M0 & \multicolumn{2}{|c|}{ Ausente } \\
\hline M1a & \multicolumn{2}{|c|}{ Pele, subcutâneo ou linfonodos metastáticos distantes } \\
\hline M1b & \multicolumn{2}{|c|}{ Metástase pulmonar } \\
\hline M1c & \multicolumn{2}{|c|}{ Todas as outras metástases viscerais } \\
\hline
\end{tabular}

$\dagger$ Macrometástases são definidas como linfonodos metastáticos detectados clinicamente e confirmados histopatologicamente. 


\section{Anexo B}

\section{DRC}

A célula de reação dinâmica (DRC) é um acessório que pode ser adicionado ao ICPMS para reduzir interferências espectrais entre íons e moléculas formadas pela combinação de espécies abundantes no gás do plasma, no solvente e na matriz da amostra. Ele atua como uma interface entre as lentes e o analisador de massa e promove a reação íon-molécula para conter as interferências e, assim, realçar a sensibilidade do analito. Este dispositivo consiste em um quadrupolo que pode ser pressurizado com um gás de reação e se comporta como um dispositivo multipolo de transferência de íons, figura B.1 [Tanner, 2000; Hattendorf, 2000].

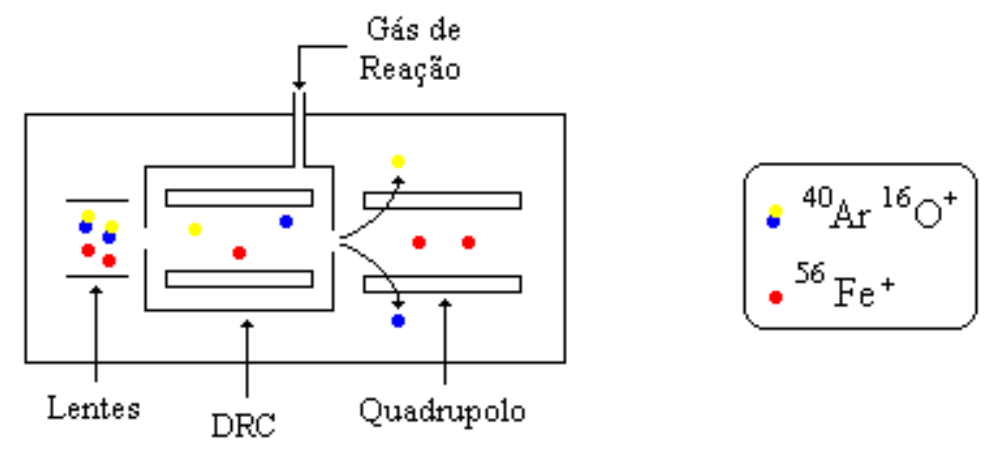

Figura B.1 Esquema de um DRC acoplado a um ICP-MS. O DRC é um quadrupolo que pode ser pressurizado com um gás de reação.

A reação íon-molécula ocorre entre o gás reativo e as espécies do feixe de íons. Estas reações transformam interferentes em produtos que não interferem com o analito. A equação B.1 mostra alguns exemplos de reações com a amônia $\left(\mathrm{NH}_{3}\right)$ e o hidrogênio $\left(\mathrm{H}_{2}\right)$, dois materiais que podem ser usados como gases de reação. Para a determinação do ${ }^{52} \mathrm{Cr}^{+}$e do ${ }^{53} \mathrm{Cr}^{+}$as interferências com alguns cloretos como o ${ }^{35} \mathrm{Cl}^{16} \mathrm{OH}^{+}(\mathrm{m} / \mathrm{z} 52)$ e o ${ }^{37} \mathrm{Cl}^{16} \mathrm{O}^{+}(\mathrm{m} / \mathrm{z} 53)$ 
podem ser resolvidas com o uso da amônia. Já para as interferências do ${ }^{40} \mathrm{Ar}^{35} \mathrm{Cl}^{+}$sobre o arsênio $\left({ }^{75} \mathrm{As}^{+}\right)$, uma boa alternativa é usar o hidrogênio como gás de reação [Neubauer, 1999].

Nota-se que estas reações (equação B.1) reduzem significativamente algumas interferências, mas em alguns casos o uso do DRC induz a formação de produtos de reação que, dependendo do gás usado, podem introduzir novas interferências que não são comuns em uma operação padrão do ICP-MS. Por isso, para experimentos que não necessitam do DRC o fluxo de gás é cortado e o acessório é isolado para dar saída ao analito [Tanner, 1999; Hattendorf, 2000].

$$
\begin{gathered}
\mathrm{ClOH}^{+} \mathrm{NH}_{3} \rightarrow \mathrm{ClO}+\mathrm{NH}_{4}^{+} \\
\mathrm{ClO}^{+} \mathrm{NH}_{3} \rightarrow \mathrm{ClO}+\mathrm{NH}_{3}^{+} \\
\mathrm{ArCl}^{+}+\mathrm{H}_{2} \rightarrow \mathrm{ArH} \mathrm{H}_{2}^{+}+\mathrm{HCl}
\end{gathered}
$$

Alguns estudos de razões isotrópicas são usados para demonstrar a extensão da redução de interferências e para ilustrar o potencial do DRC na determinação de elementos traço em matrizes que são previamente consideradas como difíceis de serem analisadas pelo ICP-MS, quando devidamente aplicado [Neubauer, 1999]. 


\section{Anexo C}

\section{TERMO DE CONSENTIMENTO LIVRE E ESCLARECIDO}

\section{Medida de Elementos-Traço em Soro Sanguíneo por meio dos Métodos PIXE e ICP-MS para Diagnóstico Precoce de Melanoma}

Este é um convite à participação de um estudo em pesquisa clínica. A proposta desse estudo é avaliar a medida de elementos traço em soro sanguíneo pelos métodos PIXE e ICPMS como fator prognóstico nos pacientes portadores de melanoma cutâneo.

As amostras de sangue de pacientes com identificação clínica de melanoma e ainda sem tratamento cirúrgico definitivo, quimioterápico ou radioterápico deverão ser coletadas no laboratório do Hospital São Paulo por ocasião da coleta de sangue de rotina na admissão/diagnóstico.

O objetivo deste trabalho é investigar possíveis alterações e estabelecer correlações do teor desses elementos em soro sanguíneo de pacientes com melanoma, com o intuito de colaborar para o diagnóstico precoce da doença.

\section{Benefícios}

Não há benefício direto ao doador no presente estudo. Porém o melanoma é um tumor agressivo que apresenta alta letalidade. Assim, o diagnóstico precoce e a conduta terapêutica nessa neoplasia constituem fatores críticos para a sobrevida dos pacientes, tornando a pesquisa importante para benefício de todos.

\section{Custo financeiro}

Aos pacientes não será cobrado nenhum ônus extra pelo fato de aderirem ao protocolo da pesquisa clínica.

\section{Privacidade}

Sua identidade será mantida em segredo durante todo o seu tratamento e seguimento. Seu nome não será utilizado em qualquer publicação que provenha dos resultados deste estudo. Os dados obtidos serão utilizados somente para esta pesquisa.

\section{Direito de se recusar e de se retirar do estudo}

Você tem o direito de se recusar a entrar e/ ou se retirar deste estudo a qualquer momento, sem nenhum prejuízo para seu tratamento e acompanhamento clínico e, também, sem nenhum preconceito por todos os profissionais da saúde envolvidos no seu tratamento e seguimento. 


\section{Garantia de acesso}

Em qualquer etapa do estudo, você terá acesso aos profissionais responsáveis pela pesquisa para esclarecimento de eventuais dúvidas. O principal investigador é o Dr. IVAN DUNSHEE DE ABRANCHES OLIVEIRA SANTOS que pode ser encontrado no endereço RUA NAPOLEÃO DE BARROS, 715, 4 ANDAR, telefone (11) 5576-4068 ou (11)55764073, e-mail: dra.afo@terra.com.br. E, se você tiver alguma consideração ou dúvida sobre a ética da pesquisa, entre em contato com o Comitê de Ética em Pesquisa (CEP) - Rua Botucatu, $572-1^{\circ}$ andar - cj 14, 5571-1062, FAX: 5539-7162 - E-mail: cepunifesp@epm.com.br.

Você tem pleno direito de ser mantido atualizado sobre os resultados parciais das pesquisas, ou de resultados que sejam do conhecimento dos pesquisadores, podendo ser obtido por meio do telefone e e-mail acima mencionados.

Em caso de dano pessoal, diretamente causado pelos procedimentos ou tratamentos propostos neste estudo (nexo causal comprovado), o participante tem direito a tratamento médico na Instituição, bem como às indenizações legalmente estabelecidas.

"Acredito ter sido suficientemente informado a respeito das informações que li ou que foram lidas para mim, descrevendo o estudo Medida de Elementos-Traço em Soro Sanguíneo por meio dos Métodos PIXE e ICP-MS para Diagnóstico Precoce de Melanoma".

"Ficaram claros para mim quais são os propósitos do estudo, os procedimentos a serem realizados, seus desconfortos e riscos, as garantias de confidencialidade e de esclarecimentos permanentes. Ficou claro também que minha participação é isenta de despesas e que tenho garantia do acesso a tratamento hospitalar quando necessário. Concordo voluntariamente em participar deste estudo e poderei retirar o meu consentimento a qualquer momento, antes ou durante o mesmo, sem penalidades ou prejuízo ou perda de qualquer benefício que eu possa ter adquirido, ou no meu atendimento neste Serviço."

Assinatura do paciente/representante legal Data

Assinatura da testemunha

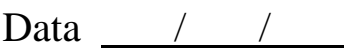

Para casos de pacientes menores de 18 anos, analfabetos, semi-analfabetos ou portadores de deficiência auditiva ou visual.

(Somente para o responsável do projeto): Declaro que obtive de forma apropriada e voluntária o Consentimento Livre e Esclarecido deste paciente ou representante legal para a participação neste estudo. 


\section{HISTÓRICO DA SAÚDE}

Dados

Nome

Data e nascimento

Sexo

RG:

Endereço:

Fone:

Histórico da família - Pais e Avos Maternos e/ou Paternos

\begin{tabular}{l|l|l|l}
\hline \multicolumn{1}{c}{ Algum parente contraiu } & Sim & Não & Grau de parentesco \\
\hline Câncer & & & \\
\hline Diabete & & & \\
\hline Doença cardíaca & & & \\
\hline Doença digestiva & & & \\
\hline Hiper. arterial (pressão alta) & & & \\
\hline Outros & & & \\
\hline
\end{tabular}

Histórico do doador

\begin{tabular}{l|l|l|l}
\hline \multicolumn{1}{c|}{ Marcar itens que contraiu } & Sim & não & desconhece \\
\hline Catapora (Varicela) & & & \\
\hline Caxumba & & & \\
\hline Rubéola & & & \\
\hline Sarampo & & & \\
\hline Asma/Bronquite & & & \\
\hline Hiper. arterial (pressão alta) & & & \\
\hline Diabete & & & \\
\hline Doença cardíaca & & & \\
\hline Doença de fígado & & & \\
\hline Doença de pele & & & \\
\hline Doença do estômago & & & \\
\hline Doença nervosa & & & \\
\hline Doença renal & & & \\
\hline Pneumonia & & & \\
\hline Sinusite & & & \\
\hline Outros & & &
\end{tabular}

Hábitos

\begin{tabular}{l|l|l|l|l}
\hline \multicolumn{1}{c|}{ Marcar cada item } & sim & não & quantidade & freqüência \\
\hline Fuma (cigarro/charuto, etc.) & & & & \\
\hline Bebidas alcoólicas & & & & \\
\hline Faz uso de medicamentos & & & & \\
\hline Pratica esporte (qual modalidade) & & & & \\
\hline
\end{tabular}

Declaração sobre o atual estado de saúde, com as próprias palavras:

São Paulo, de de 20 


\section{Anexo D}

\section{Descontaminação de materiais}

Os frascos reutilizáveis de teflon foram descontaminados seguindo os seguintes passos:

1) Lavar os objetos com detergente comum;

2) Enxaguar bem ( 10 vezes) em água corrente;

3) Deixar submerso em solução de detergente Extran (5\%) durante 24 horas;

4) Colocar 5 minutos em cuba lavadora ultrassônica;

5) Enxaguar com água destilada e desmineralizada;

6) Deixar submerso em solução de ácido nítrico PA (10\%) durante 24 horas;

7) Enxaguar com água destilada e desmineralizada;

8) Deixar submerso em água destilada e desmineralizada durante 24 horas;

9) Enxaguar com água destilada e desmineralizada.

Este protocolo de limpeza é indicado para lavar objetos utilizados na preparação de amostras cujas concentrações elementares são da ordem de $\mathrm{mg} \mathrm{kg}^{-1}$. Para valores muito baixos, da ordem de $\mu \mathrm{g} \mathrm{kg}^{-1}$ ou $\mathrm{ng} \mathrm{kg}^{-1}$, recomenda-se a substituição da água destilada/desmineralizada pela água Milli-Q e o ácido nítrico PA pelo ácido destilado. 


\section{Anexo $E$}

\section{Liofilização}

A liofilização é um processo de remoção da água do produto por sublimação, que por sua vez, ocorre quando a água no estado sólido é convertida diretamente em vapor, sem passar pelo estado líquido. A figura E.1 mostra o diagrama de fases da água, com pressão em função da temperatura. Ao longo da linha de sublimação as fases sólida e vapor estão em equilíbrio. Assim, quando a temperatura se eleva à pressão constante, sendo esta inferior à pressão do ponto triplo (como representa a linha $\mathrm{AB}$ ), a substância passa diretamente da fase sólida para a de vapor [Van Wylen, 1970].

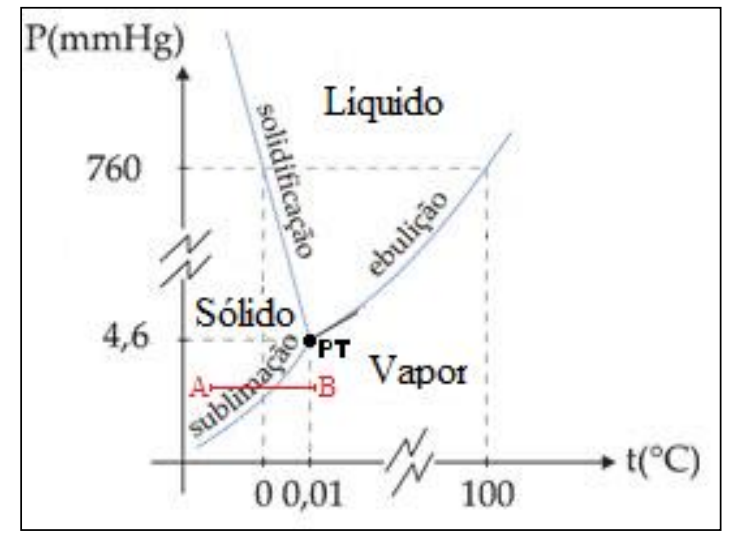

Figura E.1 Diagrama de fases para a água [Adaptado de: Portal de Estudos em Química].

As principais fases deste processo de secagem são o congelamento do produto a ser liofilizado, a secagem primária e a secundária. A secagem primária ${ }^{1}$ é conseguida com um fornecimento de calor suficiente para sublimar o gelo a baixa temperatura (2840 J por grama

\footnotetext{
${ }^{1}$ Elimina $90 \%$ da água e resulta num produto com $15 \%$ de umidade.
} 
de gelo). Na secagem secundária ${ }^{2}$ praticamente toda a umidade restante na amostra é eliminada. Nesta etapa ocorre a elevação rápida da temperatura do produto, até aproximadamente $25^{\circ} \mathrm{C}$. Essa temperatura deve ser mantida por mais seis horas para garantir a eliminação da umidade restante na amostra [Lima, 2004 e Tanaka, 1987].

Uma desvantagem da liofilização é a sua longa duração (de 1 a 3 dias). Isso ocorre devido à baixa transferência de calor dentro do produto, assim como a baixa pressão de operação [Lima, 2004]. O processo pode ser acelerado fornecendo energia ao sistema na forma de calor, que por sua vez deve ser cuidadosamente controlado para manter as condições ideias de liofilização. É extremamente importante que a temperatura de liofilização seja equilibrada entre a temperatura que mantém a integridade do produto congelado e a temperatura que maximiza a pressão de vapor do produto. Este balanço é a chave para otimizar o processo. A relação entre a pressão de vapor do gelo e a temperatura é descrita pelo gráfico da figura E.2 [Labconco, 1998].

A estrutura resultante da liofilização é uma matriz porosa, constituída do sólido do produto, que pode ser reconstituída com água instantaneamente. Os poros aparecem onde antes existiam os cristais de gelo [Mellor, 1987].

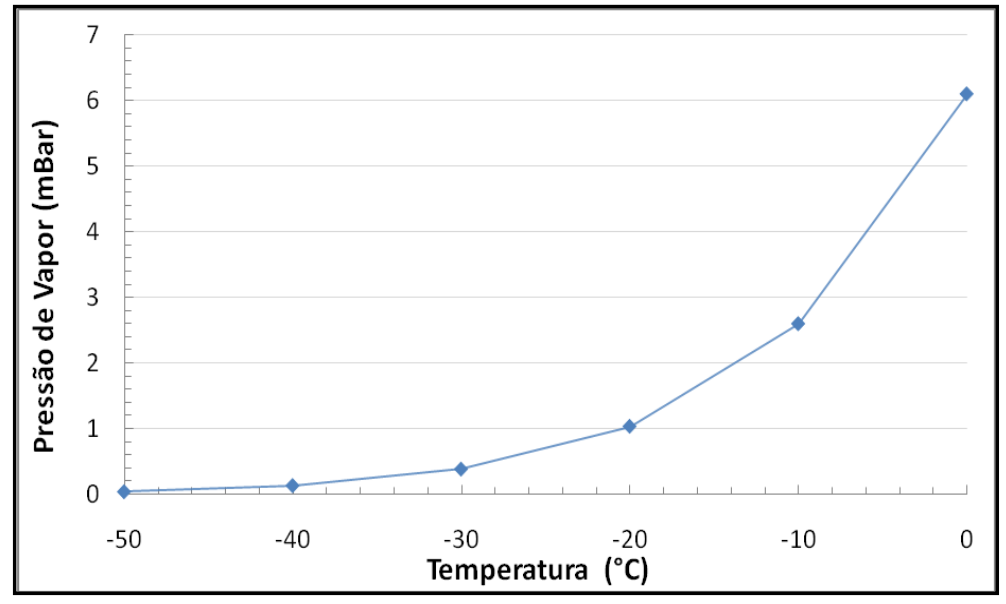

Figura E.2 Gráfico da pressão de vapor do gelo em função da temperatura [Labconco, 1998].

\footnotetext{
${ }^{2}$ Elimina mais $10 \%$ da água deixando o material liofilizado com apenas $2 \%$ de umidade.
} 


\section{Anexo F}

\section{Testes Estatísticos}

\section{F.1 Testes de Normalidade}

O teste de normalidade é uma premissa considerada ao avaliar o uso da estatística paramétrica. A hipótese assumida é que a curva de distribuição dos dados de uma população siga uma distribuição normal [Zar,1999]. Na literatura, é possível encontrar vários testes de normalidade como D’Agostino-Pearson, Kolmogorov-Smirnov, Cramér-von Mises, Anderson-Darling e Shapiro-Wilk, que verificam se a distribuição de um conjunto de dados descreve uma distribuição normal [Santos, 2003]. Cabe observar que, para grandes amostras, as diferenças entre os métodos são mínimas, porém para pequenas amostras elas podem ser significativas [Martinez-Espinosa, 2004]. O teste de normalidade de Shapiro-Wilk, também conhecido com teste $\mathrm{W}$, é o mais adequado para o estudo de pequenas populações $(\mathrm{N}<50)$, apesar de alguns autores atestarem que ele também pode ser usado para $\mathrm{N}>50$ [Conover, 1980]. Neste trabalho, foram aplicados os testes de normalidade de Kolmogorov-Smirnov e o

teste $\mathrm{W}$ para $\mathrm{N}>50$ e $\mathrm{N}<50$, respectivamente. O teste Kolmogorov - Smirnov de ajuste de curva de distribuição é baseado na máxima diferença entre a distribuição cumulativa empírica e a hipotética, ou seja, o quanto a probabilidade da curva de distribuição de duas populações são diferentes entre si [Massey Jr, 1951].

\section{F.2 Testes $\boldsymbol{t}$ de Student}

O teste $t$ de Student é um teste paramétrico que pode ser utilizado para comparar duas médias de amostras independentes ou emparelhadas. A aplicação deste teste exige que as variáveis comparadas tenham distribuição normal ou aproximadamente normal [Motta, 2006]. 


\section{F.3 Teste $U$ de Mann-Whitney}

O teste $U$ de Mann-Whitney é o teste não paramétrico correspondente ao teste $t$ de Student para comparar duas amostras independentes. Ele pode ser usado para avaliar se duas amostras pertencem à mesma população. Os cálculos são feitos em relação às medianas dos dois grupos [Motta, 2006].

\section{F.4 Análises Multivariadas}

As análises multivariadas empregadas neste trabalho foram: análise de cluster, análise fatorial, análise de variância (Manova) e teste de Kruskal-Wallis.

\section{I) Análise Fatorial}

A análise fatorial pode ser utilizada para examinar as relações existentes entre um grande número de variáveis com o objetivo de tentar resumir as informações contidas nas variáveis originais em um conjunto menor de novas variáveis, chamadas de fatores comuns que possuem uma combinação linear com os dados originais. De modo geral, o que se espera é que as variáveis originais sejam agrupadas em subconjuntos de novas variáveis alternativas que sumarizam as principais características iniciais com uma perda mínima de informações, ou seja, esta análise tenta encontrar correlações intra grupo, sendo inviável para comparações inter grupos [Mingoti, 2007 e Hair, 2009].

\section{II) Análise de Cluster}

A análise de agrupamento, também conhecida como cluster, tem como objetivo agregar objetos, ou população, de forma que os elementos pertencentes a um mesmo grupo sejam similares entre si com base nas características que neles foram medidas (variáveis). Ela supõe que os elementos de grupos diferentes são heterogêneos em relação às mesmas 
características. A ideia é maximizar a homogeneidade de objetos dentro de grupos, ao mesmo tempo em que se maximiza a heterogeneidade entre os grupos.

A análise de agrupamento é semelhante à análise fatorial no sentido de avaliar a estrutura. Porém, enquanto a primeira está interessada em agregar objetos, a segunda busca agregar variáveis. Além disso, a análise fatorial faz os agrupamentos com base em correlação de dados, enquanto a análise de agrupamento faz agregados baseados em distância (ex. distância euclidiana, distância generalizada e distância de Minkowsky) [Mingoti, 2007 e Hair, 2009].

\section{III) Análise Multivariada de Variância}

A análise multivariada de variância (MANOVA) é uma extensão da análise de variância (ANOVA) para mais de uma variável dependente. É uma técnica de dependência que examina as diferenças para duas ou mais variáveis dependentes simultaneamente, com base em um conjunto de variáveis categóricas que atuam como variáveis independentes (características). De um modo geral, esta análise é usada para avaliar diferenças entre grupos com múltiplas variáveis métricas dependentes quanto à significância estatística [Hair, 2009].

\section{IV) Análise de Kruskal-Wallis}

A análise de Kruskal-Wallis é um teste não paramétrico similar à análise ANOVA de variância com a diferença de comparar duas amostras em relação à mediana dos grupos e não em relação aos valores médios. Ele pode ser usado para comparar várias amostras independentes [Motta, 1996 e Pinheiro 1994]. 